\title{
Development of a Vaping Machine for the Sampling of THC and CBD Aerosols Generated by Two Portable Dry Herb Cannabis Vaporisers
}

\author{
Laura Carrara Christian Giroud Nicolas Concha-Lozano \\ Forensic Toxicology and Chemistry Unit, University Centre of Legal Medicine Lausanne, Lausanne, Switzerland
}

\section{Keywords}

Cannabis · CBD $\cdot$ THC $\cdot$ Vaping machine $\cdot$ Vaporiser

\begin{abstract}
Cannabis sativa is known for its recreational use, but also for its therapeutic potential. There has been wide discussion over the use of cannabis for medical purposes in recent years, especially because a consensus has not been reached regarding its risk/benefit balance. Among the more common modes of administration, vaping with a vaporiser is most frequently used for self-medication. Vaping seems to be a better alternative to preventing adverse health effects due to toxic compounds produced during combustion when cannabis is smoked. However, the delivery kinetics and efficiency of most portable vaporisers are not fully characterised with an appropriate vaping regime. This determination requires a specific vaping machine operating under realistic puffing conditions. In this study, a vaping machine was conceived to fit with the common uses of portable vaporisers that requires conditions different from those used for electronic cigarettes. The experimental setup in this study was optimised to sample aerosolised cannabinoids. The delivery kinetics, efficiency, and decarboxylation yields of two com-
\end{abstract}

mercially available vaporisers (DaVinci ${ }^{\circledR}$ and Mighty Medic ${ }^{\circledR}$ ) were evaluated for delta-9-tetrahydrocannabinol (THC) and cannabidiol (CBD). Among all tested sampling supports, the glass fibre filter is the most efficient medium to collect mixed THC and CBD aerosols. From the delivery kinetics of cannabinoids, a single-parameter model was used to calculate the extraction coefficient of each vaporiser. The results show that the Mighty Medic ${ }^{\circledR}$ vaporiser had a higher extraction coefficient (0.39) and a more immediate release of cannabinoids than the DaVinci ${ }^{\circledR}$ vaporiser $(0.16)$, which had a gradual and slower rate of vaporisation. This parameter could be a quantitative input in pharmacokinetic models of administration of volatile compounds using vaporisers and a useful tool for the comparison of vaporisers.

(c) 2020 The Author(s)
Published by S. Karger AG, Basel

\section{Introduction}

The medical use of cannabis, either prescribed or selfmedicated, is becoming ever more popular and the social pressure to legalise its use is increasing [1]. Swiss law considers cannabis a narcotic drug, and the therapeutic administration of its flower tops is not yet allowed. Cur-

\begin{tabular}{|c|c|}
\hline KARGER & $\begin{array}{l}\text { (c) } 2020 \text { The Author(s) } \\
\text { Published by S. Karger AG, Basel }\end{array}$ \\
\hline $\begin{array}{l}\text { E-Mail karger@karger.com } \\
\text { www.karger.com/mca }\end{array}$ & $\begin{array}{l}\text { This article is licensed under the Creative Commons Attribution- } \\
\text { NonCommercial-NoDerivatives } 4.0 \text { International License (CC BY- } \\
\text { NC-ND) (http://www.karger.com/Services/OpenAccessLicense). } \\
\text { Usage and distribution for commercial purposes as well as any dis- } \\
\text { tribution of modified material requires written permission. }\end{array}$ \\
\hline
\end{tabular}

Nicolas Concha-Lozano

Unité de toxicologie et chimie forensiques (UTCF)

Centre Universitaire Romand de Médecine Légale

Rue du Bugnon 19, CH-1011 Lausanne (Switzerland)

E-Mail nicolas.concha-lozano@ chuv.ch 
rently, only one product is licensed for sale. As in many other countries, a delta-9-tetrahydrocannabinol (THC) and cannabidiol (CBD) 1:1 from standardised cannabis extracts can be administered as an oromucosal spray (Sativex ${ }^{\circledR}$ ) to reduce spasticity symptoms in multiple sclerosis [2]. In Switzerland, the use of cannabis is limited to a few applications, such as the treatment of chronic pain and spastic disorders related to multiple sclerosis or nausea induced by chemotherapy [3].

Cannabis sativa L. (Cannabaceae) is a plant with controversial medicinal benefits resulting from lack of rigorous randomised double-blind, placebo-controlled studies $[4,5]$. Nevertheless, according to Zettl et al. [6], the efficacy of the THC-CBD oromucosal spray has been proven in randomised, controlled clinical studies. The dose and frequency of consumption [7], the usual co-use of cannabis and tobacco [8], the age at the beginning of consumption $[9,10]$, the routes of administration, and the context and the profiles of users significantly influence the effects and reactions of consumers of cannabis extracts and/or raw flower tops [11]. In addition, a small number of users appear to be especially vulnerable to the side effects and addictive properties of cannabis [12]. This vulnerability is very likely under genetic [13] and environmental influence [14]. To be supported by the Swiss public health system, any treatment must be adequate, effective, and economical [15].

Because of its high price, in Switzerland, cannabis medical treatment is not systematically reimbursed through insurance and is instead treated on a case-bycase basis [16]. For these reasons, people commonly purchase cannabis on the legal or black market for self-medication. In contrast to medically accepted dosage forms such as oral pills or sublingual sprays, raw cannabis is generally smoked as joints when self-medicated, either with or without tobacco present. One of the main motivations for this use is to manage insomnia disorders [17]. The inhalation of cannabis joints is certainly the most popular administration method for those who practice self-medication, but also among recreational and compulsive users [7]. The combustion and volatilisation of cannabinoids is improved by mixing cannabis with tobacco [18]. Through this route of administration, the delivery of cannabinoids is rapid and efficient. However, smoking of cannabis, especially when mixed with tobacco, may be harmful for the consumer [7] and for those who passively inhale the side-stream smoke.

For the sake of harm reduction, vaporisation of raw cannabis flower tops at low temperatures is preferred over combustion of mixtures of cannabis and tobacco at

A Vaping Machine to Assess the THC and CBD Delivery of Vaporisers high temperature $\left(700-900^{\circ} \mathrm{C}\right)$ [19]. Combustion of these plant materials generates a wide range of toxic pyrolysis substances. Furthermore, the combined inhalation of nicotine and THC induces dual drug dependence and addiction. The vaporisation of raw cannabis below its combustion point (about $230^{\circ} \mathrm{C}$ ) reduces the formation of toxic by-products and the occurrence of pulmonary symptoms [20]. Since tobacco is not needed, the risks of dependence and addiction caused by nicotine inhalation are reduced. Compared to the oral route that is slow to cause an effect, unpredictable and with interindividual variability in pharmacokinetics [21], vaporisation provides delivery characteristics (yield and kinetic) that are considered very similar to those of smoking. The only requirement is that the temperature of the heating chamber prefilled with grinded cannabis flower tops be high enough $\left(>100^{\circ} \mathrm{C}\right)$ to rapidly convert all the acidic precursors (THC acid A [THCA] and cannabidiolic acid [CBDA]) of the cannabinoids into their corresponding active and neutral forms (THC and CBD) $[22,23]$ and to subsequently vaporise them.

Depending on the wanted effect the users will select different varieties and chemovars [24]. Cannabis smoked for its euphoric and intoxicating properties is generally very rich in THC and poor in $\mathrm{CBD}$, while a more balanced composition between THC and CBD is preferred for medical cannabis. When combined with THC, high doses of $\mathrm{CBD}$ reduce the intoxicating and unwanted side effects of THC [25]. The presence of other substances, such as terpenes (e.g., myrcene and caryophyllene), which influence the aroma and pharmacological properties of cannabis strains through their synergistic ("entourage") effect [26], may also play a role in consumer choice. One of the advantages of vaporisation is an early onset of the effects, which start between 5 and 10 min compared to oral administration that is significantly delayed in its effects (60-180 $\mathrm{min})$ [20].

Many options and at least three main classes of electronic devices exist for the aerosolisation of cannabinoids: desktop stationary vaporisers that are unfit for transport - e.g., Volcano ${ }^{\circledR}$ (Storz \& Bickel, Tuttlingen, Germany) [27, 28]; e-liquid portable atomisers from ecigarettes that are dedicated to the vaporisation of propylene glycol/glycerol cannabinoid mixtures [29-31]; and hand-held portable dry herb vaporisers $[32,33]$. When compared to desktop devices, portable vaporisers have the advantage of being small, easily transportable, discreet, easy to use, cordless, and reasonably priced. Nowadays there is a wide variety of equipment that is marketed, easily purchased on the web, and constantly changing and

Med Cannabis Cannabinoids 2020;3:84-93 85 
evolving (e.g., vaporisers described by Red Vape [34]). Some vaporisers are offered for sale for very short periods, while others seem to be more successful and remain available for purchase for a longer time. Commercially available cannabis vaporisers differ in design, construction, handling, and performance. A rapid and easy method to assess the pros and cons and to evaluate the suitability and effectiveness under realistic conditions of these vaporisers is necessary to sort all existing equipment and offer patients the most appropriate portable vaporisers able to alleviate their pathology.

These portable electronic vaporisers must gradually deliver a therapeutic dose of cannabinoids in a reasonable number of puffs. The slow incrementation of doses combined with titration of effects should minimise the risks of unwanted adverse effects $[35,36]$. Therapeutic unit doses, vaporised and typical for raw cannabis flower tops, are about $2-5 \mathrm{mg}$ for THC. For medical indications, many patients obtain some benefits with daily oral doses of 5-20 mg of CBD. The effective dose of CBD administered as an aerosol using a vaporiser is not yet known $[4,20]$. However, a few recent, randomised, placebo-controlled trials used vaporisation (especially with desktop vaporisers) as a means of cannabinoid administration. CBD was inhaled at doses ranging from 4 to $400 \mathrm{mg}$ in combination with or without THC [25]. Forensic investigations were also carried out, but with varieties rich in THC and low in CBD as preferred by most recreational users [37]. Epidemiological studies reported that about one-third of US patients enrolled in an electronic survey were using vaporisation, while still the majority preferred to smoke conventional joints [38].

In this study, we evaluated two commercially available portable vaporisers for their vaporisation efficiency and delivery performance using a homemade vaping machine. Various configurations of the machine were tested. The inhalation pattern was standardised to assess inhaling rates, volumes, and puff durations as well as interpuff intervals that are as close as possible to real-life conditions. We also put the focus on finding the best cannabinoid aerosol sampling materials. To this aim, we evaluated different types of sampling media. We also discuss the pros and cons of two vaping devices used in this study and make recommendations for adequate use of cannabis vaporisers.

\section{Materials and Methods}

Chemicals

Pharmaceutical-grade cannabis female flower tops Bedi$\mathrm{ol}^{\circledR}$ - rated THC 5.0\% (w/w) and CBD 7.5\% (w/w) (sum of the acidic and neutral forms) - were obtained from Bedrocan International BV (Veendam, The Netherlands). Cannabinoid standards were purchased from Lipomed AG (Arlesheim, Switzerland): THC (Dronabinol), $1 \mathrm{mg} / \mathrm{mL}$ in ethanol; THCA, $1 \mathrm{mg} / \mathrm{mL}$ in isopropanol; $\mathrm{CBD}, 1 \mathrm{mg} / \mathrm{mL}$ in methanol $(\mathrm{MeOH}) ; \mathrm{CBDA}$, $1 \mathrm{mg} / \mathrm{mL}$ in acetonitrile; and cannabinol (CBN), $1 \mathrm{mg} / \mathrm{mL}$ in $\mathrm{MeOH}$. All organic solvents, dichloromethane, $\mathrm{MeOH}$, acetone, and formic acid were of analytical grade (Sigma-Aldrich [Buchs, Switzerland] or Merck). Glass fibre filters (Whatman GFB, i.d. $37 \mathrm{~mm}$ ) mounted in a styrene holder (SKC Inc., USA) were provided by VWR (Schlieren, Switzerland). Empty cartridges (EZPak, i.d. $21.4 \mathrm{~mm}$, length $80 \mathrm{~mm}$ ) were provided by BGB Analytik (Böckten, Switzerland) and filled with $15 \mathrm{~g}$ of polyaromatic adsorbent resin for hydrophobic compounds (XAD2, Amberlite with a particle size of $250-700 \mu \mathrm{m}$ ) provided by Sigma-Aldrich.

\section{Vaporisers}

Two vaporisers with distinct heating modes were tested. The first vaporiser, mainly employed for medical purposes (Mighty Medic ${ }^{\circledR}$ from Storz \& Bickel), has a hybrid heating system combining convection (the air is heated and then sucked through the cannabis) and conduction. The second vaporiser (DaVinci ${ }^{\circledR}$ vaporiser from Organicix LLC) works only by conduction, the cannabis being directly in contact with the heating part. The choice of these vaporisers among other available products was based on sales data and grey literature available in Switzerland. These two brands are top sellers and readily available in shops and via the Internet.

\section{Experimental Setup}

A vaping machine was made to generate large puffs consistent with the use of vaporisers. Most vaping/smoking machines used to test tobacco cigarettes or e-liquid electronic cigarettes have a limited puff volume, usually between 35 and $100 \mathrm{~mL}$, which complies with common standards $[39,40]$. This range of volumes aims to reproduce a puff controlled by the oral cavity volume. However, inhalation through a vaporiser is more usually related to the larger thoracic volume. Due to the lack of experimental data, the volume of air breathed for each 5-s puff corresponds to the low value of the standard volume of air inhaled by a person at rest. The inhalation topography is assumed to be similar to the one described by Wilsey et al. [41]. A volume of approximately $500 \mathrm{~mL}$ was also used in experiments aiming to develop a puff topography instrument for high flow rate smoking devices, such as narghile water pipe and chicha [42, 43]. The inhaled puff volume generated by these devices is very likely similar to that of portable vaporisers. A picture and a schematic representation of the machine are shown in Figure 1. A first circuit connects the vaporiser mouthpiece, the front and back sampling medium, and the pump. A second circuit connects a dummy sampling medium to the pump. This double circuit prevents sudden variations in flow when the solenoid valves are switched. The main airflow of a diaphragm pump was adjusted to $6 \mathrm{~L} / \mathrm{min}$ with a needle valve using a calibrated carbonpiston flowmeter (Dry-Cal DC Lite; Bios, USA). The puffs are triggered by the opening of valve V2 and the simultaneous closing of valve $\mathrm{V} 1$. The vaping regime was set to generate a $500-\mathrm{mL}$ puff lasting $5 \mathrm{~s}$ with a frequency of 2 puffs/min. Valves and delays were controlled by a microcontroller with a puff counter (Arduino ${ }^{\circledR}$ development board).
Med Cannabis Cannabinoids 2020;3:84-93 DOI: $10.1159 / 000505027$
Carrara/Giroud/Concha-Lozano 
Table 1. Summary of experimental conditions

\begin{tabular}{llll}
\hline Sampling support & Number of puffs & Vaporiser & $\begin{array}{l}\text { Replicates/ } \\
\text { experiment }\end{array}$ \\
\hline XAD2 cartridge & $0-1-2-5-10-20-30$ & $\begin{array}{l}\text { DaVinci }^{\circledR} \\
\text { Mighty Medic }^{\circledR}\end{array}$ & 1 \\
\hline Glass filter & $0-5-10-15-20$ & DaVinci $^{\circledR}$ & 1 \\
& & Mighty Medic $^{\circledR}$ & 1 \\
\hline XAD2 cartridge & 10 & DaVinci $^{\circledR}$ & 10 \\
& 10 & Mighty Medic $^{\circledR}$ & 7 \\
\hline Glass filter & 10 & DaVinci $^{\circledR}$ & 4 \\
& & Mighty Medic $^{\circledR}$ & 4 \\
\hline XAD2 cartridge and glass filter & 10 & DaVinci $^{\circledR}$ & 3 \\
& & Mighty Medic $^{\circledR}$ & 3 \\
\hline
\end{tabular}

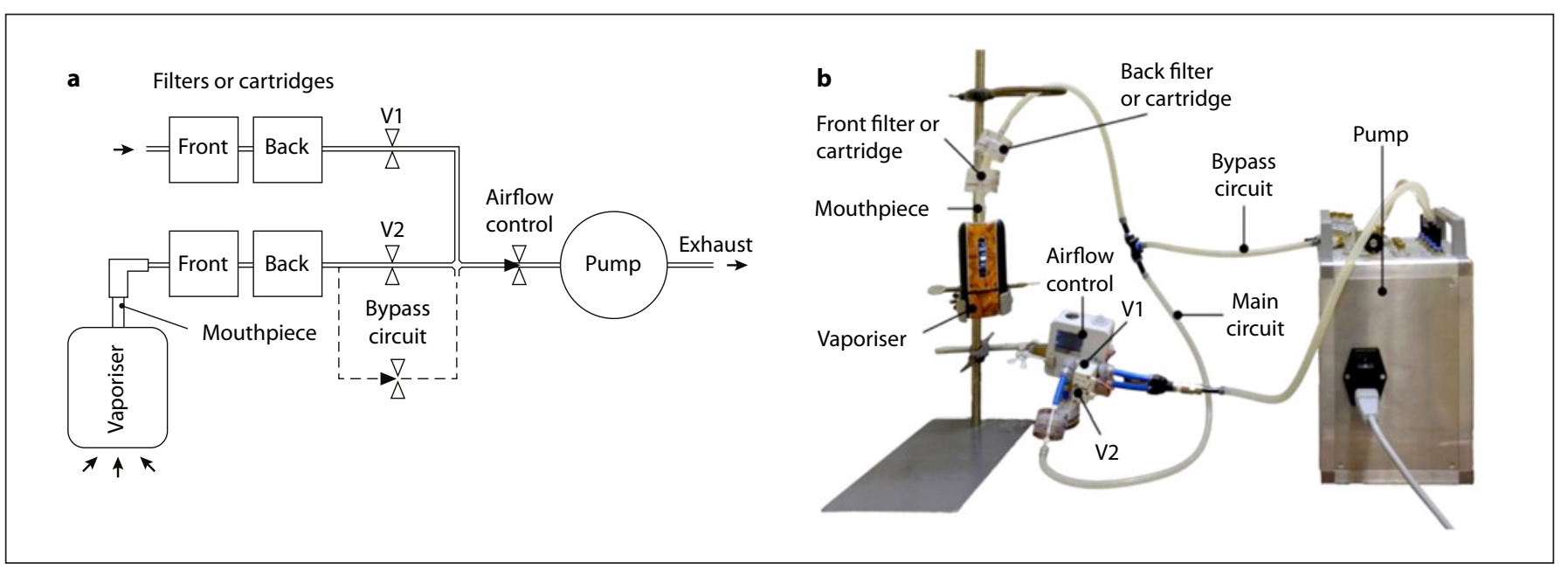

Fig. 1. Diagram (a) and image (b) of the vaping machine and the experimental setup.

Vapour Generation and Sampling

For each test, $150 \mathrm{mg}$ of finely ground cannabis flower tops were introduced into the vaporiser heating chamber. The vaporiser was then turned on and the temperature set to $210^{\circ} \mathrm{C}$, the maximum temperature shared by both devices. Once the set temperature was reached, the first 5-s puff was triggered after $25 \mathrm{~s}$. Depending on the experiment this 30 -s pattern was repeated between 1 and 30 times (Table 1).

$\mathrm{XAD} 2$ cartridges were desorbed four times with $10-\mathrm{mL}$ portions of $\mathrm{MeOH}$. Glass filters were immersed in three successive volumes of $10 \mathrm{~mL}$ of $\mathrm{MeOH}$, vortexed, and left stand for a minimum of $30 \mathrm{~min}$. For each sampling support, all the portions were pulled together before analysis. After each assay, the mouthpieces and the inner parts of the vaporisers were washed in $30 \mathrm{~mL}$ of $\mathrm{MeOH}$ to recover the condensed fraction.

In order to evaluate the loss of volatile compounds by leakage or diffusion through the body of the vaporiser, preliminary experiments were carried out with and without a bypass circuit (Fig. 1). The bypass circuit is a small residual air flow $(0.06 \mathrm{~mL} /$ min) used to maintain a small negative pressure in the vaporiser body between puffs, which keeps vaporised compounds in the system. Subsequently, all experiments were carried out with the open derivation circuit in order to be able to calculate the global mass balance.

Finally, after the vapour generation, the remaining plant heated residues were extracted with $8 \mathrm{~mL}$ of $\mathrm{MeOH} /$ dichloromethane $(9: 1 \mathrm{v} / \mathrm{v})$, sonicated for $10 \mathrm{~min}$, agitated for $20 \mathrm{~min}$ on a reciprocal horizontal shaker, and then centrifuged for $20 \mathrm{~min}$ at 3,400 rpm. The supernatant was transferred to a graduated flask and adjusted to $10 \mathrm{~mL}$ with $\mathrm{MeOH}$.

Table 1 summarises all the experiments carried out during the study and indicates the tested experimental conditions. Thirtyfive experiments were performed in total and the data issued from each puffing session were analysed and used to determine a kinetic puffing profile and to calculate the vaporisation yield for each vaporiser. The results also allowed us to calculate the recovery efficiency for both sampling media, i.e., XAD2 and glass fibre filters. 
Table 2. Results of the experiments carried out to measure the recovery efficiency of two supports: percentage of THC and CBD recovered on XAD2 and glass fibre filters using the Mighty Medic ${ }^{\circledR}$ vaporiser

\begin{tabular}{|c|c|c|c|c|}
\hline \multirow{3}{*}{$\begin{array}{l}\text { Percent of the loaded amount }(150 \mathrm{mg} \text { of Bediol } \\
\text { flower tops) } \\
\text { THC: } 7.5 \mathrm{mg}=100 \% \\
\text { CBD: } 11.2 \mathrm{mg}=100 \%\end{array}$} & \multicolumn{4}{|c|}{ Type of sampling support } \\
\hline & \multicolumn{2}{|c|}{$\begin{array}{l}\text { front: glass fibre filter } \\
\text { back: glass fibre filter }\end{array}$} & \multicolumn{2}{|c|}{$\begin{array}{l}\text { front: XAD2 cartridge } \\
\text { back: glass fibre filter }\end{array}$} \\
\hline & THC & $\mathrm{CBD}$ & THC & $\mathrm{CBD}$ \\
\hline (1) Front support & $84 \%$ & $76 \%$ & $51 \%$ & $52 \%$ \\
\hline (2) Back support & $0 \%$ & $0 \%$ & $19 \%$ & $17 \%$ \\
\hline Recovery efficiency (1) / [(1) + (2)] & $100 \%$ & $100 \%$ & $73 \%$ & $75 \%$ \\
\hline
\end{tabular}

Sampling Support Recovery Efficiency

The recovery efficiency was calculated from the amount found in the front and back supports (Table 2). Six experiments were carried out with two sampling supports connected in series: XAD2 cartridge or glass fibre filters in front position, and glass fibre filters in back position.

\section{Optimal Desorption Volume}

The minimum volume required to desorb the cannabinoids from the sampling supports was determined by using successive unit volumes of $\mathrm{MeOH}$ to wash a sampling support after a 10-puff session. Each unit volume of $10 \mathrm{~mL}$ was separately collected and analysed by high-performance liquid chromatography coupled to diode array detection (HPLC-DAD, Agilent 1100).

\section{Cannabinoid Identification and Quantification}

Unequivocal identification of the main neutral cannabinoids was performed by gas chromatography-mass spectrometry (GCMS) [44]. Native acid precursors (THCA and CBDA) of neutral cannabinoids were identified after silylation with N-methyl-N(trimethylsilyl)trifluoroacetamide. Terpenes were tentatively identified using the NIST 2017 mass spectra database. Quantification of cannabinoids of plant material extracts, wall condensates, unheated and heated cannabis flower top residues, and aerosols collected in various sampling media were performed by HPLC-DAD (Agilent 1100) for all main five cannabinoids (THC, THCA, CBD, CBDA, and $\mathrm{CBN}$ ) [44]. The injection volume was $10 \mu \mathrm{L}$. Cannabinoids were separated on a Macherey-Nagel 250/3 Nucleodur 100-5 C8ec reversed-phase column ( $5 \mu \mathrm{m}$ particle size). Two eluents were used: $\mathrm{A}=\mathrm{MeOH}$-deionised water $(1: 1 \mathrm{v} / \mathrm{v})$ with $25 \mathrm{~mm}$ formic acid, and $\mathrm{B}=\mathrm{MeOH}$ with $25 \mathrm{~mm}$ formic acid. Linear gradient elution was obtained by mixing increasing amounts of eluent B (from 40 to $100 \%$ in $25 \mathrm{~min}$ ). The column oven was set at $45^{\circ} \mathrm{C}$. Absorption signals of cannabinoids were monitored at 210, 222, and $275 \mathrm{~nm}$ (bandwidth $=5 \mathrm{~nm}$ ). The reference wavelength was fixed at $450 \mathrm{~nm}$ (bandwidth $=50 \mathrm{~nm}$ ). Calibration curves were prepared with increasing concentrations of cannabinoids for each standard $(0,1,2$, $5,10,25,50,75$, and $100 \mu \mathrm{g} / \mathrm{mL}$ ) [45]. Validation was obtained by seven repetitive analyses of six quality controls from 10 to $100 \mu \mathrm{g} /$ $\mathrm{mL}$ for three successive days. Interday and intermediate precisions for THC and $\mathrm{CBD}$ were $<5 \%$ except for the lowest quality control level $(10 \mu \mathrm{g} / \mathrm{mL})$ for which it was $<15 \%$. The limit of quantification was $5 \mu \mathrm{g} / \mathrm{mL}$ and the limit of detection was $1 \mu \mathrm{g} / \mathrm{mL}$. The coefficient of correlation was $>0.99$ for all cannabinoids [45].

\section{Results and Discussion}

\section{Identification and Quantitation of Cannabinoids in Bediol $^{\circledR}$ Flower Tops}

In Bediol ${ }^{\circledR}$ tops extract, neutral and acidic forms of THC, CBD and also traces of cannabigerol, cannabichromene, and CBN were identified by GC-MS. Quantification by HPLC-DAD of THC/THCA and CBD/CBDA was $5.0 \%(\mathrm{w} / \mathrm{w})$ and $7.5 \%(\mathrm{w} / \mathrm{w})$, respectively.

\section{Decarboxylation Yield}

For both vaporisers neither the acidic precursors THCA nor CBDA were detected in the cannabis residue or the vapour after four puffs. The decarboxylation is therefore considered complete already after $2 \mathrm{~min}$.

\section{Optimal Desorption Volume}

After two successive washes of the glass fibre filter, the third $10-\mathrm{mL}$ portion contained a quantity of cannabinoids below the limit of quantification. Therefore, the optimal desorption volume for the glass fibre filter was set to three portions of $10 \mathrm{~mL}$. Using the same approach, the optimal volume of XAD2 cartridge desorption was set to four portions of $10 \mathrm{~mL}$.

\section{Sampling Media Recovery Efficiency}

The recovery efficiency of the glass fibre filters was $>99 \%$ for both THC and CBD. For the XAD2 cartridge, the recovery efficiency was significantly lower, with values of 73 and $75 \%$ for THC and CBD, respectively. The low recovery efficiency could be due to several factors: (1) the high air flow through the support that leads to a reduced total capacity of the media, (2) the large particle size of the medium that reduces the air/resin interaction, (3) a non-optimised compaction of the filling medium that promotes the formation of wide air passages, (4) the low affinity of the phase with the cannabinoids, and 
Table 3. Percentage of the total amount of THC or CBD loaded in the vaporisers, calculated for the sampling support, residue, and mouthpiece after ten puffs (total time for ten puffs with intervals: $5 \mathrm{~min}$ )

\begin{tabular}{|c|c|c|c|c|c|c|c|c|}
\hline & \multicolumn{4}{|c|}{ DaVinci ${ }^{\circledR}$ vaporiser } & \multicolumn{4}{|c|}{ Mighty Medic ${ }^{\circledR}$ vaporiser } \\
\hline & \multicolumn{2}{|c|}{ glass fibre filter } & \multicolumn{2}{|l|}{ XAD2 } & \multicolumn{2}{|c|}{ glass fibre filter } & \multicolumn{2}{|l|}{$\mathrm{XAD} 2$} \\
\hline & THC & CBD & THC & $\mathrm{CBD}$ & THC & $\mathrm{CBD}$ & THC & $\mathrm{CBD}$ \\
\hline Sampling support, \% & $42 \pm 6$ & $43 \pm 5$ & $19 \pm 14$ & $26 \pm 13$ & $84 \pm 4$ & $76 \pm 4$ & $57 \pm 11$ & $60 \pm 14$ \\
\hline Residue, \% & $34 \pm 8$ & $28 \pm 6$ & $50 \pm 12$ & $41 \pm 8$ & $0 \pm 0$ & $2 \pm 0.4$ & $0 \pm 0$ & $2 \pm 0.5$ \\
\hline Mouthpiece, \% & $12 \pm 2$ & $13 \pm 2$ & $9 \pm 1$ & $11 \pm 1$ & $24 \pm 1$ & $21 \pm 0.5$ & $24 \pm 1$ & $21 \pm 1$ \\
\hline Total, \% & $88 \pm 7$ & $84 \pm 5$ & $78 \pm 8$ & $78 \pm 8$ & $108 \pm 4$ & $99 \pm 4$ & $81 \pm 12$ & $83 \pm 15$ \\
\hline
\end{tabular}

(5) the saturation of the medium surface by other compounds. Among these factors, it is likely that it is the strong airflow and the coarse particle size of the medium that decrease the recovery efficiency of cartridges for cannabinoid aerosols. Unlike the XAD2 resin, glass fibre filters captured all the cannabinoids, probably due to the low porosity and highly specific surface of the filters, which favour aerosol impaction.

However, at present there is poor knowledge regarding the physicochemical properties of vaporiser aerosols [46], and further elucidation of these characteristics is needed for a better understanding of their interaction with different sampling supports.

\section{Global Vaporisation Efficiency}

During the preliminary experiments, tests were performed with and without the bypass circuit (Fig. 1). The comparison of the two configurations allowed us to estimate leakage losses of about $20 \%$ for the DaVinci ${ }^{\circledR}$ vaporiser and $24 \%$ for the Mighty Medic ${ }^{\circledR}$ vaporiser after ten puffs. These losses could be due to the internal geometry of the devices and the tightness of the closing seals.

Table 3 shows the percentage of the total amount of THC or CBD loaded in the vaporisers found in the sampling support, the residual plant material, and the mouthpiece after ten puffs.

Using results from the glass fibre filters, for the Mighty Medic ${ }^{\circledR}$ vaporiser, the amount of vaporised THC and $\mathrm{CBD}$ was 84 and $76 \%$, respectively. In the residue, these percentages were $<1 \%$ and $2 \%$ for THC and CBD, respectively. About $24 \%$ of THC and $21 \%$ of CBD were found in the mouthpiece of the vaporiser. The total amount found in the vapour phase, in the residue, and in the mouthpiece was about $100 \%$. For this device, the vaporisation of cannabinoids is considered complete after ten puffs.

A Vaping Machine to Assess the THC and

CBD Delivery of Vaporisers
For the DaVinci ${ }^{\circledR}$ vaporiser, the amount of vaporised THC and CBD was 42 and 43\%, respectively. In the residual plant material, these percentages were 35 and $28 \%$ for THC and CBD, respectively. About $12 \%$ of THC and $13 \%$ of CBD were found in the mouthpiece of the vaporiser. The total amount found in the vapour phase, in the residue, and in the mouthpiece was $<88 \%$. For this device, the vaporisation of cannabinoids is not complete after ten puffs, and the mass balance shows a loss of about 12 and $16 \%$ for THC and CBD, respectively. We suggest that these losses can be explained by the hollow cavity under the heating chamber of this device, which could lead to the loss of a few fragments of cannabis material, and also by the fact that one of the moving parts of the retractable mouthpiece was not desorbed.

\section{Kinetics of Cannabinoid Delivery}

A kinetic profile of cannabinoid delivery (from 0 to 20 puffs) was performed for each vaporiser using either $\mathrm{XAD} 2$ cartridges or glass fibre filters. Figure 2 shows the amounts of THC and CBD found in the residue, the mouthpiece, and the trapping support versus the number of puffs. After five puffs, $>90 \%$ of the cannabinoids were vaporised by the Mighty Medic ${ }^{\circledR}$ vaporiser, while only half of the cannabinoids were vaporised with the DaVin$\mathrm{ci}^{\circledR}$ device. For the Mighty Medic ${ }^{\circledR}$, the vaporiser rate was higher compared to the DaVinci ${ }^{\circledR}$, and the cannabinoids reached a non-detectable amount between 10 and 15 puffs in the residue.

The THC and CBD content in the plant residue of the DaVinci ${ }^{\circledR}$ vaporiser presented a more gradual decrease. Twenty puffs were not enough to vaporise the total cannabinoids loaded in the heating chamber. For both vaporisers, small amounts of cannabinoids condensed in the mouthpiece, and these quantities marginally increased over time with the number of puffs.

Med Cannabis Cannabinoids 2020;3:84-93 DOI: $10.1159 / 000505027$ 


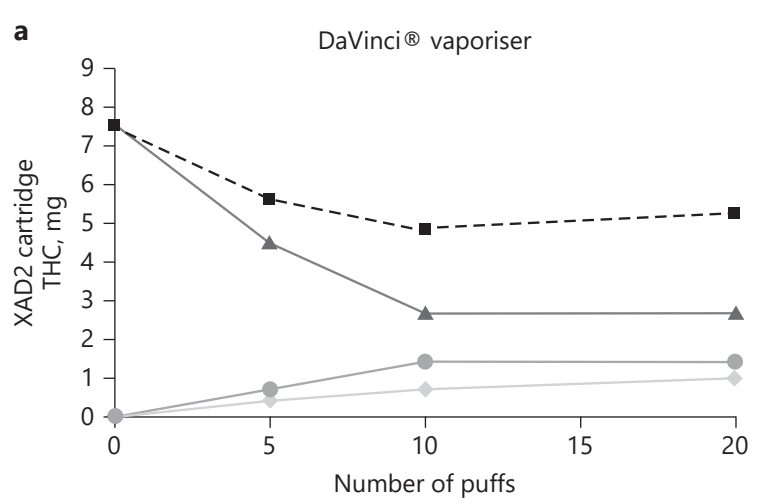

THC
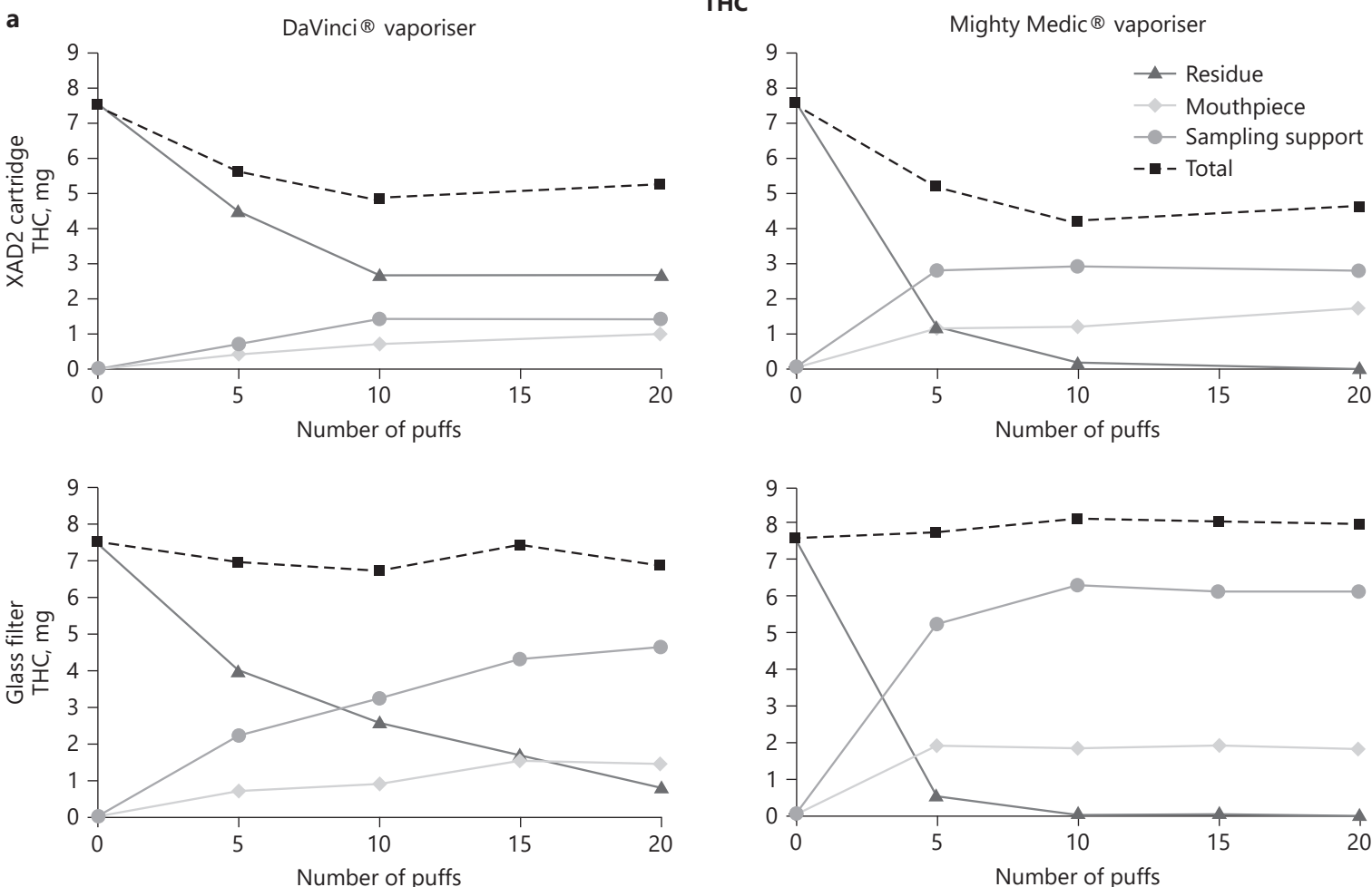

b

DaVinci ${ }^{\circledR}$ vaporiser
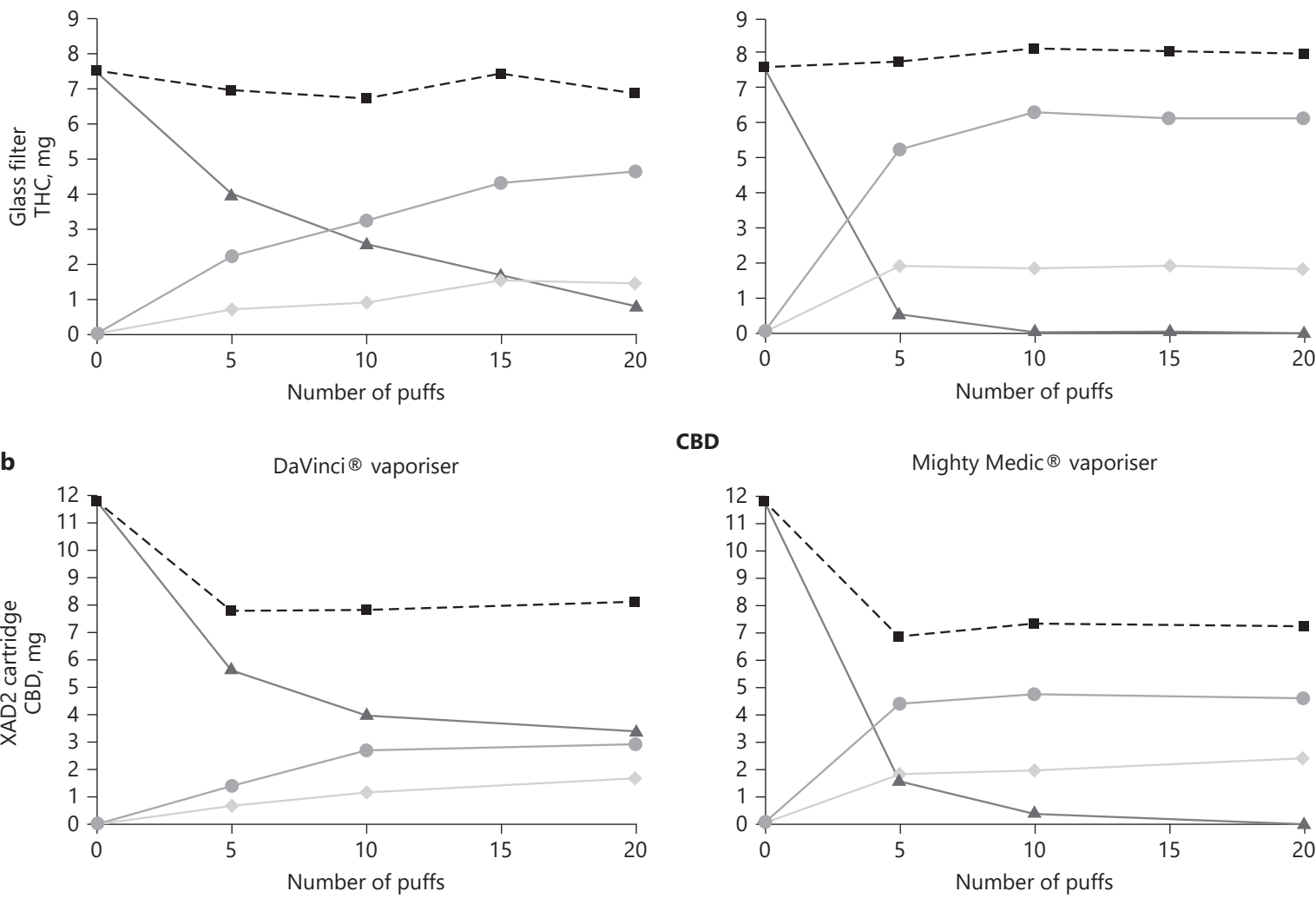

CBD
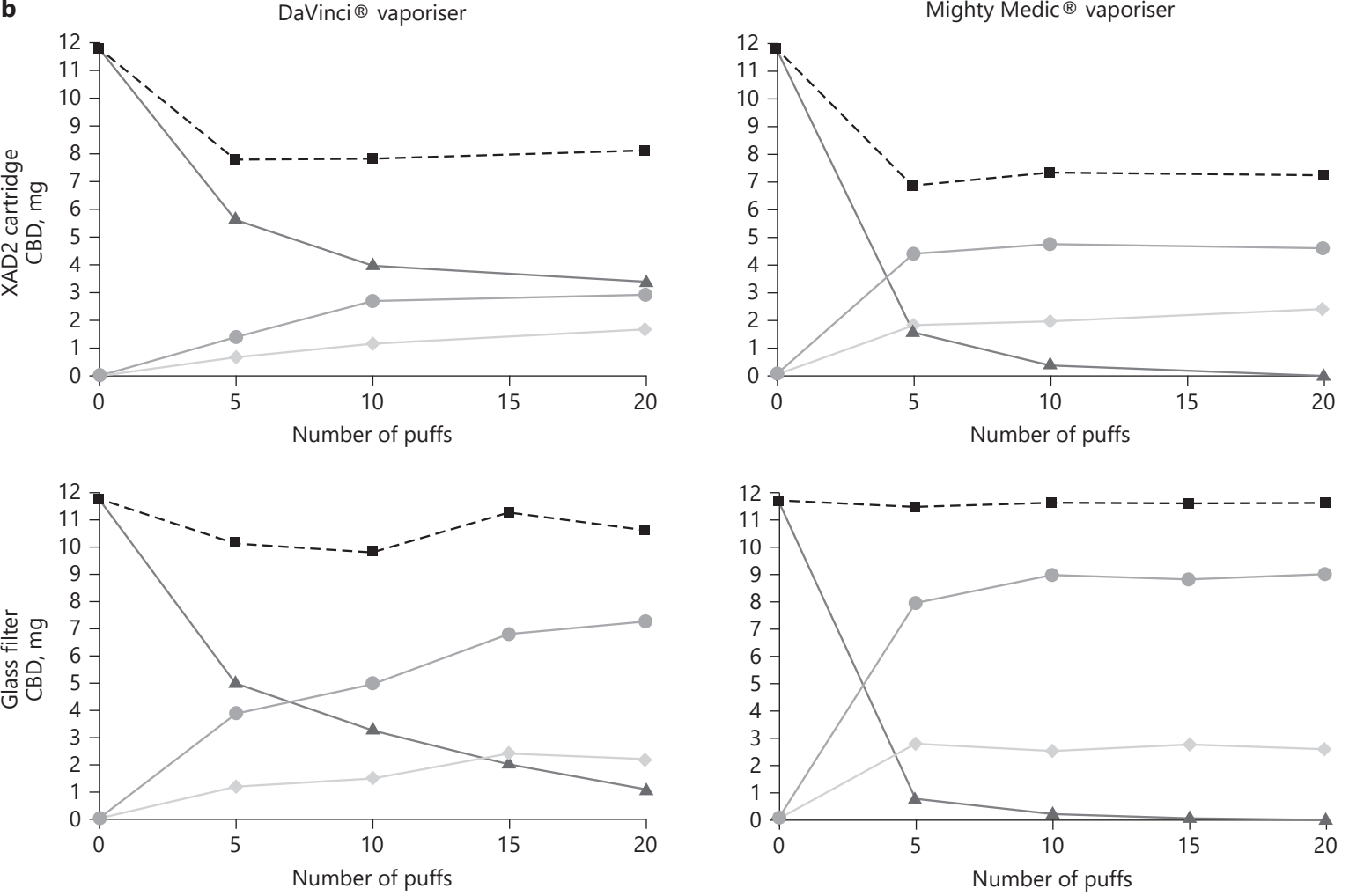

Fig. 2. Kinetic profiles of THC (a) and CBD (b) amounts found in different parts of the vaping machine connected to the DaVinci ${ }^{\circledR}$ or Mighty Medic $^{\circledR}$ vaporisers and using either XAD2 cartridges or glass fibre filters as sampling support (total time for 20 puffs and interpuffs: 10 min). 
Differences in delivery kinetics could be explained by the mode of heat transfer, resistance the device creates during each puff, the geometry of the filling chamber, the path of the airflow, and other factors. Both convection and conduction occur in the Mighty Medic ${ }^{\circledR}$ vaporiser, while only conduction is used in the DaVinci ${ }^{\circledR}$ device. The DaVinci ${ }^{\circledR}$ vaporiser is usually employed for recreational purposes, and a more gradual cannabinoid delivery rate could be preferred by the users. This pattern of delivery could also be an advantage for new patients for whom a slow incrementation of cannabis doses could be more appropriate and prescribed [20].

\section{Kinetic Modelling}

The amount of cannabinoids per puff decreased rapidly for both vaporisers (Fig. 3). For each puff, the sum of volatile compounds transferred into the vapour was a fraction of the total amount available in the heating chamber. Assuming that this fraction is a constant, a simple kinetic model of the quantity of vaporised cannabinoids $\mathrm{Q}_{\mathrm{V}}$ in $\mathrm{mg}$ could be defined as follows:

$$
\frac{d Q_{v}}{d P}=\left(Q_{\max }-Q_{v}\right) k_{e}
$$

where $\mathrm{P}$ is the number of puffs, $\mathrm{Q}_{\max }$ is the maximal quantity in $\mathrm{mg}$ that can be extracted, and $\mathrm{k}_{\mathrm{e}}$ is the extraction coefficient. The integrated form of this equation can then be written as follows:

$$
Q_{v}=Q_{\max }-Q_{\max } e^{-k e P}
$$

Finally, the vaporised amount $\mathrm{Q}_{\mathrm{v}}$ can be expressed as a percentage of the maximal quantity that can be extracted $-Q_{\max }$ in $\mathrm{mg}$ :

$$
Q_{v} \%=\frac{Q_{v}}{Q_{\max }} \times 100=100-100 e^{-k e P}
$$

Fitting our experimental data $\mathrm{Q}_{\mathrm{v}} \%$ versus the number of puffs using equation 3 allows for the estimation of the $\mathrm{k}_{\mathrm{e}}$ parameter for both vaporisers. A linear least squares regression method was performed (Fig. 3). Here, the extraction coefficient of the DaVinci ${ }^{\circledR}$ device $\left(k_{e}=0.16\right)$ is smaller than the $\mathrm{k}_{\mathrm{e}}$ value for the Mighty Medic ${ }^{\circledR}$ device $\left(\mathrm{k}_{\mathrm{e}}=0.39\right)$. The extraction coefficient can be interpreted so that the Mighty Medic ${ }^{\circledR}$ extracts about $39 \%$ of the available cannabinoids in the heating chamber per puff, while the DaVinci ${ }^{\circledR}$ vaporiser extracts only $16 \%$. No significant difference in the $\mathrm{k}_{\mathrm{e}}$ value was found between $\mathrm{CBD}$ and THC. The similar vaporisation kinetics of both cannabinoids may be due to the very close vapour pres-

A Vaping Machine to Assess the THC and CBD Delivery of Vaporisers

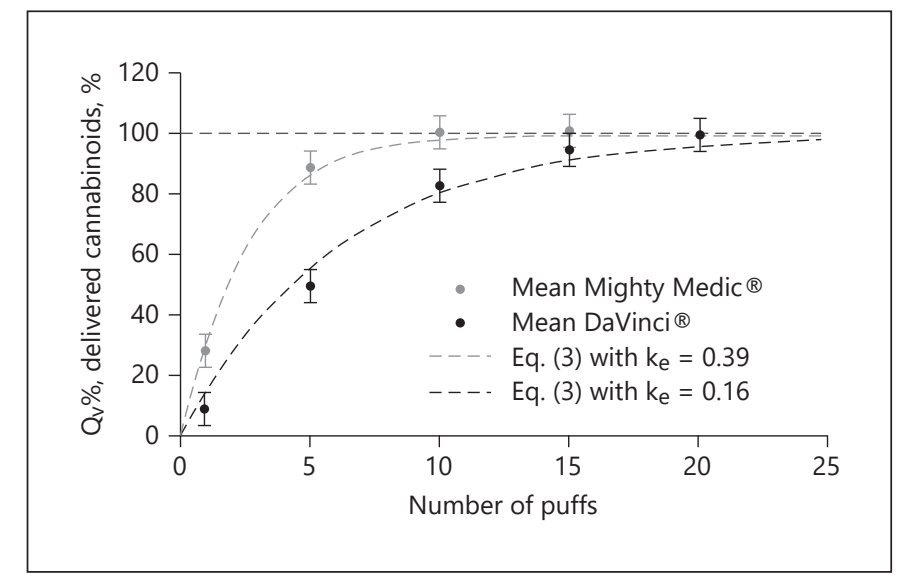

Fig. 3. Cannabinoid content in the aerosol expressed in percent of the final vaporised quantity.

sure of THC and CBD above $140^{\circ} \mathrm{C}$ and to their similar temperature of decarboxylation [47]. The heat transfer modes of the heating chamber could explain the differences in $\mathrm{k}_{\mathrm{e}}$. The temperature drops during a puff in the DaVinci ${ }^{\circledR}$ vaporiser could be higher than in the Mighty $\mathrm{Medic}^{\circledR}$ vaporiser where the air inlet is preheated. Although the vaporisation is faster for the Mighty Medic ${ }^{\circledR}$, the DaVinci ${ }^{\circledR}$ allows a more gradual dosage, with $90 \%$ of the dose delivered after fifteen puffs.

In the literature, we found several attempts to design efficient vaping systems to trap cannabis aerosols. Good efficiency in collecting cannabinoids was achieved using a table vaporiser with a fibre glass filter by Hazekamp et al. [27]. Lanz et al. [47] tested five commercial vaporisers and also found that the decarboxylation efficiency was almost complete after $3 \mathrm{~min}$ of continuous aspiration at $420 \mathrm{mbar}$ with a temperature set at $210^{\circ} \mathrm{C}$. However, their experimental design differed from ours in that they operated under continuous aspiration conditions while we used more realistic aspiration/rest cycle conditions. Hädener et al. [48] used a vaping machine but for dabbing butane hash oil, while Sheehan et al. [49] used a smoking machine to characterise the chemical and physical composition of cannabis smoke. This underlines the need to standardise experimental conditions for testing portable cannabis vaporisers.

\section{Conclusion}

An experimental setup was developed to generate vaporiser puffs under realistic conditions of use taking into account the volume, frequency, and duration of puffs. 
Different sampling media and two vaporisers were compared. The glass fibre filter appeared to be the most appropriate sampling medium for THC and CBD cannabinoids, even with an airflow up to $6 \mathrm{~L} / \mathrm{min}$. From the delivery kinetics observed for the two vaporisers, a oneparameter model is proposed. We suggest that this kinetic model, based on the extraction coefficient, could be adapted for comparing devices to each other. Mighty Medic $^{\circledR}$ vaporisers have an extraction coefficient of 0.39 and the DaVinci ${ }^{\circledR}$ vaporiser has an extraction coefficient of 0.16 . This parameter could be a quantitative input in pharmacokinetic models of administration of volatile compounds using vaporisers.

\section{Acknowledgments}

The authors gratefully acknowledge Storz \& Bickel for providing the Mighty Medic ${ }^{\circledR}$ vaporiser.

\section{Statement of Ethics}

The authors have no ethical conflicts to disclose.

\section{Disclosure Statement}

The authors have no financial or competing interests.

\section{Author Contributions}

C. Giroud and N. Concha-Lozano conceived and designed the experiments. L. Carrara performed the experiments. L. Carrara, C. Giroud, and N. Concha-Lozano analysed the data. L. Carrara, C. Giroud, and N. Concha-Lozano wrote the paper.

\section{References}

1 Aston ER, Scott B, Farris SG. A qualitative analysis of cannabis vaporization among medical users. Exp Clin Psychopharmacol. 2019 Aug;27(4):301-8.

2 Russo M, Naro A, Leo A, Sessa E, D’Aleo G, Bramanti P, et al. Evaluating Sativex ${ }^{\circledR}$ in Neuropathic Pain Management: A Clinical and Neurophysiological Assessment in Multiple Sclerosis. Pain Med. 2016 Jun;17(6):1145-54.

3 Kilcher G, Zwahlen M, Ritter C, Fenner L, Egger M. Medical use of cannabis in Switzerland: analysis of approved exceptional licences. Swiss Med Wkly. 2017 Jul;147:w14463.

4 Russo EB. Cannabis therapeutics and the future of neurology. Front Integr Neurosci. 2018 Oct; $12: 51$

5 European Monitoring Centre for Drugs and Drug Addiction. Medical use of cannabis and cannabinoids: questions and answers for policymaking. 2018. Available from: http://www. emcdda.europa.eu/system/files/publications/10171/20185584_TD0618186ENN_ PDF.pdf.

6 Zettl UK, Rommer P, Hipp P, Patejdl R. Evidence for the efficacy and effectiveness of THC-CBD oromucosal spray in symptom management of patients with spasticity due to multiple sclerosis. Ther Adv Neurol Disorder. 2016 Jan;9(1):9-30.

7 Fischer B, Russell C, Sabioni P, van den Brink W, Le Foll B, Hall W, et al. Lower-Risk Cannabis Use Guidelines: A Comprehensive Update of Evidence and Recommendations. Am J Public Health. 2017 Aug;107(8):e1-12.

8 Wang JB, Ramo DE, Lisha NE, Cataldo JK. Medical marijuana legalization and cigarette and marijuana co-use in adolescents and adults. Drug Alcohol Depend. 2016 Sep;166:32-8.
9 Murray RM, Quigley H, Quattrone D, Englund A, Di Forti M. Traditional marijuana, high-potency cannabis and synthetic cannabinoids: increasing risk for psychosis. World Psychiatry. 2016 Oct;15(3):195-204.

10 Jouroukhin Y, Zhu X, Shevelkin AV, Hasegawa Y, Abazyan B, Saito A, et al. Adolescent $\Delta$ 9-Tetrahydrocannabinol Exposure and Astrocyte-Specific Genetic Vulnerability Convergeon NuclearFactor- $\kappa B$-Cyclooxygenase-2 Signaling to Impair Memory in Adulthood. Biol Psychiatry. 2019 Jun;85(11):891-903.

11 Russell C, Rueda S, Room R, Tyndall M, Fischer B. Routes of administration for cannabis use - basic prevalence and related health outcomes: A scoping review and synthesis. Int J Drug Policy. 2018 Feb;52:87-96.

12 Ashton JC. Is Cannabis Harmless? Focus on Brain Function. Curr Drug Res Rev. 2019; 11(1):33-9.

13 Hiemstra M, Nelemans SA, Branje S, van Eijk $\mathrm{KR}$, Hottenga JJ, Vinkers CH, et al. Genetic vulnerability to schizophrenia is associated with cannabis use patterns during adolescence. Drug Alcohol Depend. 2018 Sep;190:143-50.

14 Verweij KJ, Zietsch BP, Lynskey MT, Medland SE, Neale MC, Martin NG, et al. Genetic and environmental influences on cannabis use initiation and problematic use: a metaanalysis of twin studies. Addiction. 2010 Mar; 105(3):417-30.

15 Conseil fédéral. Traiter les personnes gravement malades avec du cannabis. Rapport du Conseil fédéral en réponse à la Motion Kessler (14.4164). Available from: https://www.bag. admin.ch/dam/bag/fr/dokumente/npp/cannabis/bericht-br-motion-kessler $\% 20$ 14.4164_cannabis.pdf.
16 Krcevski-Skvarc N, Wells C, Häuser W. Availability and approval of cannabis-based medicines for chronic pain management and palliative/supportive care in Europe: A survey of the status in the chapters of the European Pain Federation. Eur J Pain. 2018 Mar;22(3):440-54.

17 Babson KA, Sottile J, Morabito D. Cannabis, Cannabinoids, and Sleep: a Review of the Literature. Curr Psychiatry Rep. 2017 Apr;19(4): 23.

18 Van der Kooy F, Pomahacova B, Verpoorte R. Cannabis smoke condensate II: influence of tobacco on tetrahydrocannabinol levels. Inhal Toxicol. 2009 Feb;21(2):87-90.

19 Cannabis Research A-Z. Vaporizers and Cannabis Studies Completed. 2019. Available from: https://www.calgarycmmc.com/vaporizers.htm.

20 MacCallum CA, Russo EB. Practical considerations in medical cannabis administration and dosing. Eur J Intern Med. 2018 Mar;49: 12-9.

21 Fabresse N, Becam J, Carrara L, Descoeur J, Di Mario M, Drevin G, et al. Cannabinoïdes et thérapeutique. Toxicol Anal Clin. 2019; 31(3):153-72.

22 Dussy FE, Hamberg C, Luginbühl M, Schwerzmann T, Briellmann TA. Isolation of Delta9THCA-A from hemp and analytical aspects concerning the determination of Delta9-THC in cannabis products. Forensic Sci Int. 2005 Apr;149(1):3-10.

23 Zivovinovic S, Alder R, Allenspach MD, Steuer C. Determination of cannabinoids in Cannabis sativa L. samples for recreational, medical, and forensic purposes by reversedphase liquid chromatography-ultraviolet detection. J Anal Sci Technol. 2018;9(1):27. 
24 Hazekamp A, Tejkalová K, Papadimitriou S. Cannabis: From cultivar to chemovar II - a metabolomics approach to cannabis classification. Cannabis Cannabinoid Res. 2016; $1(1): 202-15$.

25 Solowij N, Broyd S, Greenwood LM, van Hell $\mathrm{H}$, Martelozzo D, Rueb K, et al. A randomised controlled trial of vaporised $\Delta 9$-tetrahydrocannabinol and cannabidiol alone and in combination in frequent and infrequent cannabis users: acute intoxication effects. Eur Arch Psychiatry Clin Neurosci. 2019 Feb; 269(1):17-35.

26 Russo EB. Taming THC: potential cannabis synergy and phytocannabinoid-terpenoid entourage effects. Br J Pharmacol. 2011 Aug; 163(7):1344-64.

27 Hazekamp A, Ruhaak R, Zuurman L, van Gerven J, Verpoorte R. Evaluation of a vaporizing device (Volcano) for the pulmonary administration of tetrahydrocannabinol. J Pharm Sci. 2006 Jun;95(6):1308-17.

28 Solowij N, Broyd SJ, van Hell HH, Hazekamp A. A protocol for the delivery of cannabidiol (CBD) and combined CBD and $\Delta 9$-tetrahydrocannabinol (THC) by vaporisation. BMC Pharmacol Toxicol. 2014 Oct;15(1):58.

29 Breitbarth AK, Morgan J, Jones AL. E-cigarettes - an unintended illicit drug delivery system. Drug Alcohol Depend. 2018 Nov; 192: 98-111.

30 Giroud C, de Cesare M, Berthet A, Varlet V, Concha-Lozano N, Favrat B. E-Cigarettes: A Review of New Trends in Cannabis Use. Int J Environ Res Public Health. 2015 Aug;12(8): 9988-10008.

31 Varlet V, Concha-Lozano N, Berthet A, Plateel G, Favrat B, De Cesare M, et al. Drug vaping applied to cannabis: Is "Cannavaping" a therapeutic alternative to marijuana? Sci Rep. 2016 May;6(1):25599.
32 Eisenberg E, Ogintz M, Almog S. The pharmacokinetics, efficacy, safety, and ease of use of a novel portable metered-dose cannabis inhaler in patients with chronic neuropathic pain: a phase 1a study. J Pain Palliat Care Pharmacother. 2014 Sep;28(3):216-25.

33 Shiplo S, Asbridge M, Leatherdale ST, Hammond D. Medical cannabis use in Canada: vapourization and modes of delivery. Harm Reduct J. 2016 Oct;13(1):30.

34 Red Vape. Vaporizer zur Lösung von Wirkstoffen aus Pflanzen. 2019. Available from: https://www.red-vape.ch/vaporizer-geraete.

35 Gorelick DA, Heishman SJ. Methods for clinical research involving cannabis administration. Methods Mol Med. 2006;123:235-53.

36 Heishman SJ, Stitzer ML, Yingling JE. Effects of tetrahydrocannabinol content on marijuana smoking behavior, subjective reports, and performance. Pharmacol Biochem Behav. 1989 Sep;34(1):173-9.

37 Hartman RL, Brown TL, Milavetz G, Spurgin A, Gorelick DA, Gaffney G, et al. Controlled Cannabis Vaporizer Administration: Blood and Plasma Cannabinoids with and without Alcohol. Clin Chem. 2015 Jun;61(6):850-69.

38 Baron EP, Lucas P, Eades J, Hogue O. Patterns of medicinal cannabis use, strain analysis, and substitution effect among patients with migraine, headache, arthritis, and chronic pain in a medicinal cannabis cohort. J Headache Pain. 2018 May;19(1):37.

39 International Organization for Standardization. ISO 3308:2012: Routine analytical cigarette-smoking machine - definition and standard conditions. Geneva: International Organization for Standardization; 2012.

40 International Organization for Standardization. ISO 20768:2018: Vapour products - routine analytical vaping machine - definitions and standard conditions. Geneva: International Organization for Standardization; 2018 .
41 Wilsey B, Marcotte TD, Deutsch R, Zhao H, Prasad H, Phan A. An Exploratory Human Laboratory Experiment Evaluating Vaporized Cannabis in the Treatment of Neuropathic Pain From Spinal Cord Injury and Disease. J Pain. 2016 Sep;17(9):982-1000.

42 Becquemin MH, Bertholon JF, Attoui M, Roy F, Roy M, Dautzenberg B. Particle size in water pipe smoke. Rev Mal Respir. 2008 Sep; 25(7):839-46. French.

43 Shihadeh A, Antonios C, Azar S. A portable, low-resistance puff topography instrument for pulsating, high-flow smoking devices. Behav Res Methods. 2005 Feb;37(1):186-91

44 Hazekamp A, Peltenburg A, Verpoorte R, Giroud $\mathrm{C}$. Chromatographic and spectroscopic data of cannabinoids from Cannabis sativa $\mathrm{L}$. J Liq Chromatogr Relat Technol. 2005;28(15): 2361-82.

45 Giroud C. Analysis of cannabinoids in hemp plants. Chimia (Aarau). 2002;56(3):80-3.

46 Jaques P, Zalay M, Huang A, Jee K, Schick SF, editors. Measuring aerosol particle emissions from cannabis vaporization and dabbing. The 15th Meeting of the International Society for Indoor Air Quality and Climate, 2018, Philadelphia, PA, USA.

47 Lanz C, Mattsson J, Soydaner U, Brenneisen R. Medicinal Cannabis: In Vitro Validation of Vaporizers for the Smoke-Free Inhalation of Cannabis.PLoSOne.2016Jan;11(1):e0147286.

48 Hädener M, Vieten S, Weinmann W, Mahler $\mathrm{H}$. A preliminary investigation of lung availability of cannabinoids by smoking marijuana or dabbing $\mathrm{BHO}$ and decarboxylation rate of THC- and CBD-acids. Forensic Sci Int. 2019 Feb;295:207-12.

49 Sheehan TJ, Hamnett HJ, Beasley R, Fitzmaurice PS. Chemical and physical variations of cannabis smoke from a variety of cannabis samples in New Zealand. Forensic Sci Rev. 2018 Apr;4(2):168-78 